\title{
CULTURA E PATRIMÓNIO, PARADIGMAS DE DESENVOLVIMENTO
}

\begin{abstract}
João L. Inês $\operatorname{Vaz}^{1}$
Resumo: $O$ autor começa por definir o que entende por cultura e depois apresenta as apostas na cultura e no património como alternativas económicas no interior deprimido e abandonado. Aponta os exemplos do Museu Gugenheim em Bilbao, as gravuras rupestres de Vila Nova de Foz Côa, a aldeia teatral de Campo Benfeito, em plena Serra do Montemuro e o Fluviário da vila de Mora, como investimentos que alteraram o carácter dessas regiões e tornaram estes lugares gares como pólos de atracção turística.

Termina propondo a criação de Áreas Culturais, apontando como exemplo a implementar desde logo a área cultural cisterciense, na margem esquerda do rio Douro.
\end{abstract}

Palavras-chave: cultura, património, áreas culturais

Abstract: The author begins by defining what is meant by culture and then presents the stakes in culture and heritage as economic alternatives within depressed and abandoned interior. The article points to the examples of the Guggenheim Museum in Bilbao, the engravings of Vila Nova de Foz Coa, the theatrical village of Campo Benfeito, in the Serra do Montemuro and the Fluviário in the village of Mora, as investments that have changed the nature of these regions and made these places marshalling as poles of attraction.

It ends by proposing the creation of cultural areas, citing as an example to implement immediately the Cistercian cultural area on the left bank of the River Douro.

Keywords: culture, heritage, cultural areas

\footnotetext{
${ }^{1}$ Universidade Católica Portuguesa, Centro Regional das Beiras, Viseu. jlivaz@gmail.com.
} 
No dia 29 de Setembro de $2008^{2}$, a imprensa portuguesa divulgava um relatório da OCDE em que se afirmava que Portugal é um "país com assimetrias regionais acentuadas, sendo que nas áreas mais pobres investe mais na construção de equipamentos e de infra-estruturas do que na promoção de actividades que permitam a criação de emprego". Se a primeira afirmação, que Portugal tem assimetrias acentuadas, faz parte de todos os diagnósticos que se fazem ao país, já a solução proposta é nova, pois nunca até agora nenhuma entidade tinha sido tão directa ao apontar a cultura como uma das soluções para a situação de depressão portuguesa.

Como se pode ver, a OCDE propõe, como solução, para as regiões mais deprimidas, a criação de actividades que gerem emprego e não apenas novas infra-estruturas.

Noutro ponto do relatório, acrescenta-se que uma das áreas em que devem ser criados esses postos de trabalho é na área cultural. Que outro organismo poderia fazer melhor sugestão do que OCDE?

$\mathrm{O}$ interior foi abandonado durante décadas, sobrecarregou-se o litoral com os novos migrantes que criaram problemas enormes no ambiente e na ocupação do território, criaram-se bairros suburbanos onde estes rios de pessoas foram desaguar, os governantes não viram até agora que os problemas desse terço do território onde vive mais de $70 \%$ da população portuguesa só se resolvem a montante, exactamente através da criação do desenvolvimento do interior deprimido e abandonado. Criaram-se, como diz a OCDE, infra-estruturas, nomeadamente auto-estradas, mas estas mesmas estradas levam as pessoas do litoral ao interior, mas também facilitam a emigração dos habitantes do interior para o litoral. Não se cuidou de estabelecer um plano de criação de condições de manutenção das pessoas nesse mesmo interior. A industrialização deu-se no litoral, muitas autarquias do interior criaram parques industriais que estão às moscas, correndo-se hoje o risco de haver overbooking de terrenos para a instalação de indústrias, como ainda há poucas semanas o Presidente da Associação Portuguesa de Investimentos reconhecia em entrevista a um semanário, mas o interior continua deprimido, deserto e a desertificar-se cada vez mais. A agricultura não segura as pessoas, as indústrias não existem, os serviços estão sedeados nas cidades como é normal, pois faz parte do conceito de cidade, o sistema técnico - económico falhou nas suas tentativas de desenvolvimento do interior. Que resta depois disto? Apenas a conformação com o seu destino de definhamento e abandono?

\footnotetext{
${ }^{2} \mathrm{O}$ presente texto resulta de uma conferência que o autor pronunciou no dia $25 \mathrm{de}$ Outubro de 2008 no "Encontro Nacional da Associação de Auditores dos Cursos de Defesa Nacional", realizado em Viseu. Todas as referências temporais dizem respeito a esse ano, mantendo-se integralmente o texto então lido.
} 
Entendemos que apenas a aposta nos recursos endógenos, nos recursos naturais e naquilo que permanece independentemente daqueles que saíram ou estão ausentes, ou seja, a Cultura e o Património, poderá levar a um desenvolvimento desejável. Os poucos que permanecem são os detentores da cultura local e são os detentores da memória colectiva. Tomando o desenvolvimento como um "processo social de mudança, total e integrado, afectando instituições, mentalidades, valores, sistemas produtivos, sociedades e indivíduos", como o define Adolfo Casal Yanez, ele dirá respeito a toda a sociedade e não apenas àqueles que vivem no interior ou nas cidades, nas cidades grandes ou pequenas, mas é um processo que tem que envolver todos. Se o sistema técnico-económico falhou, vamos então agarrar o sistema cultural não como complemento, mas como locomotiva, pois ele tem que ser a matriz de qualquer plano que pretenda ser de desenvolvimento. Uma das razões do falhanço de todos os pseudo-planos de desenvolvimento, é que têm sido elaborados à revelia das pessoas existentes nas regiões, à revelia das populações locais que não são sequer ouvidas na sua elaboração. Como pode um burocrata em Lisboa ou um eurocrata em Bruxelas saber do que se passa nas aldeias transmontanas ou beirãs, saber que ansiedades e objectivos tem a população dessas aldeias? Só uma visão paternalista tem permitido que se elaborem planos que não têm em conta as realidades locais e quem conhece as mentalidades das pessoas do interior sabe perfeitamente que o pior que pode acontecer é as pessoas aperceberem-se de que lhes querem impor coisas que não têm nada a ver com elas e com o seu sistema cultural.

É por isso que entendo, como já disse, que todo o processo de desenvolvimento tem que levar a uma mudança, sobretudo das mentalidades, tem que ser um processo integrado e total, uma mudança por parte dos técnicos e dos decisores, mas também da parte dos atingidos. Um processo de desenvolvimento deverá ter sempre a mudança como fim último a atingir.

Entendo, repito, que a cultura deve ser a matriz do desenvolvimento e sem cultura não haverá desenvolvimento nem progresso, podendo atingirse, isso sim, aquilo a que António Sérgio chama de "falsa noção de progresso" que apenas atinge os níveis materiais e técnicos do homem. Sem progresso/mudança mental e espiritual, isto é, cultura, o progresso é apenas uma verdadeira falácia.

Esclareço que entendo por cultura todos os processos mentais e de criação espiritual do homem, correspondendo ao "ser" e "sentir" do homem, contrapondo-se assim aos processos materiais e técnicos que entram no âmbito civilizacional e em que se fazem invenções que vão mudar o "ter" do homem. A cultura entra assim no espaço da criação, mas também da herança, pois aquela terá sempre subjacente uma herança 
espiritual que o homem obteve através do seu nascimento. É esta herança que designamos por Património. Esta designação é, todavia, demasiado vasta pelo que raramente se emprega isolada, pois o seu conceito varia consoante o seu utilizador e tanto pode referir-se aos processos da cultura como aos processos técnicos, científicos, tecnológicos ou económicos. É por isso que a palavra normalmente se emprega com um adjectivo qualificativo, raramente se empregando o substantivo puro, a não ser que o contexto em que nos encontramos pressuponha a compreensão imediata do tipo de Património a que estamos a referir-nos. Por isso podemos falar de duas grandes divisões do Património, o cultural e o material. Não vamos aqui distinguir ainda as suas subdivisões, pois iremos referir-nos apenas à cultura e ao património cultural.

Sem cultura não há progresso, mas como pode a cultura contribuir para o progresso do homem, tomando aqui esta palavra no sentido do avanço dos processos materiais? Para que isto aconteça, a cultura tem que ser uma matriz na elaboração dos projectos de desenvolvimento e pode e deve mesmo ser tida em conta também nas questões económicas de um plano. Um exemplo concreto. Todos conhecem ou já ouviram falar do Museu Guggenheim de Bilbao que foi projectado por Frank Ghery e inaugurado em 1997. O museu localiza-se numa cidade que estava deprimida, em pleno Pais Vasco, e foi construído numa altura em que os movimentos separatistas estavam em actuação plena. Além da criação de postos de trabalho durante a sua construção, o museu criou ainda várias centenas de postos de trabalho directos e passou a injectar para a economia basca a módica quantia de 4 milhões de euros anuais. Afinal a cultura pode ou não pode criar riqueza? Este caso é o mais flagrante porque se tratou de um retorno imediato, mas os investimentos na cultura não costumam ser tão rentáveis a curto prazo.

São raros os investimentos que têm um retorno a curto prazo, pois o normal é o médio ou até o longo prazo e, muitas vezes, acabam por gerar lucros que inicialmente nem se previam. Mas para haver lucro tem que haver investimento e não se pode querer ter um sem o outro. Ninguém tem a pretensão de ter lucro de uma empresa se primeiro não formar a empresa e a puser a funcionar e o mesmo acontece com a cultura, pois só pode haver lucro se houver investimento, só haverá retorno depois de se fazer investimento. Mas como se pode fazer investimento cultural quando vemos o orçamento do Ministério da Cultura baixar de 1\% do PIB em 2001 para 0,2\% do mesmo PIB no próximo Orçamento de Estado? Em cultura os investimentos privados pouco existem e se entendemos que Estado não tem que ser a panaceia de todos os males, também pensamos que, neste caso concreto, o Estado tem um papel fundamental a desempenhar numa primeira fase de investimentos. 
Um dos casos culturais mais polémicos dos últimos 13 anos em Portugal foi o caso da barragem de Vila Nova de Foz Côa. Todos estamos recordados das polémicas desencadeadas pelo facto de a barragem projectada e iniciada ter sido abandonada em detrimento do salvamento das gravuras rupestres. Os ânimos de arqueólogos, engenheiros, ambientalistas e políticos vieram ao de cima e todos procuraram justificar as suas opções a favor ou contra as gravuras. O que é certo é que o investimento naquilo que seria uma das maiores barragens portuguesas foi abandonado e em seu lugar surgiu um Parque Arqueológico classificado pela UNESCO como Património da Humanidade. Posteriormente, foi projectado um grande museu que neste momento está em vias de conclusão. Treze anos passados, as feridas abertas ainda não sararam e a polémica não acabou, apesar do ruído ser muito menor. Valeu a pena abandonar um projecto económico por um projecto cultural? Dizem os detractores que não, porque a barragem traria mais benefícios económicos do que o Parque Arqueológico. Pelo contrário, dizem os defensores das gravuras. Vejamos a questão por este lado cultural. A construção da barragem atrairia a Vila Nova de Foz Côa durante 3 ou 4 anos, os anos que demoraria a sua construção, várias centenas de trabalhadores, criando-se, por consequência, muitos postos de trabalho durante esse tempo. Mas, acabada a barragem, todos os trabalhadores e técnicos se retiravam e a barragem ficava a produzir electricidade e comandada provavelmente de uma forma informática a partir de uma das centrais da EDP localizadas no Pocinho, na Bemposta ou na central de Régua. Quantos portugueses iriam visitar a barragem de Foz Côa ou quantos estrangeiros viriam de propósito fazer o mesmo?

Ora, o que é que sucedeu com a declaração das gravuras como Património Mundial e com a adopção da ideia da criação do Parque Arqueológico? Criou-se um gabinete do Parque, com técnicos, funcionários administrativos, guias arqueológicos e vigilantes. E ali estão, desde 1995, criados cerca de 50 postos de trabalho permanentes. Ali se criou a sede nacional do Centro Nacional de Arte Rupestre (CNART) que criou mais uma dúzia de postos de trabalho e que tem como missão estudar todas as gravuras rupestres existentes no nosso território. Quantos mais postos de trabalho vai criar o Museu Arqueológico? Além destes benefícios directos, temos que ver que as gravuras atraíram até 2007 mais de 170.000 visitantes, com particular destaque para os estrangeiros que ao longo dos anos têm vindo sempre a aumentar, apesar do sistema restritivo de visitas. Qual o impacto que estes turistas tiveram até agora na economia local? Pensemos em locais próximos, como o Pocinho ou a Bemposta onde existem barragens semelhantes à que se iria construir e vê-se que o impacto da construção dessas barragens na economia local foi absolutamente nulo. Pelo contrário, em Foz Côa, as gravuras tornaram-se 
o símbolo de um concelho e, diria mesmo, de uma região. Hoje, falar de Vila Nova de Foz Côa é o mesmo que falar das gravuras rupestres e desde os caixotes do lixo locais às placas de sinalização, todos ostentam a gravura rupestre como símbolo. Um dos mais significativos impactos deu-se ao nível dos vinhos produzidos pela Adega Cooperativa local que viu as suas vendas aumentarem de uma forma muito acentuada desde que os símbolos das gravuras começaram a ser usados nos rótulos. Novas casas de turismo de habitação, novos restaurantes e novos sítios de alojamento são algumas das consequências directas ou indirectas do aparecimento das gravuras.

As gravuras rupestres são hoje o símbolo nacional e internacional da região. Não será só por causa das gravuras, mas o concelho de Vila Nova de Foz Côa foi dos poucos a não diminuir a sua população na década de noventa, ao contrário de quase todos os concelhos transmontanos.

Face a isto que se passa em Vila Nova de Foz Côa, ocorre perguntar se algum outro acontecimento poderia ter um impacto tão grande na economia local como a criação do Parque Arqueológico e do CNART. Comparem-se os impactos das gravuras com o que teve a barragem do Pocinho, por exemplo, também localizada no mesmo concelho.

A sugestão da OCDE para a criação de postos de trabalho na área cultural concretizou-se plenamente em Foz Côa e ao fim destes anos parece que as estruturas criadas cumprem a sua missão.

Um outro exemplo de uma outra área totalmente diferente e menos conhecido mas que gostaria de apontar, situa-se aqui bem perto de nós, no concelho de Castro Daire. Em plena serra do Montemuro, "a mais desconhecida serra de Portugal", como lhe chamou Amorim Girão, que continua a ser hoje uma região fortemente deprimida e em que as escolas do antigo ensino primário estão praticamente todas fechadas desde há duas décadas ou até mais anos. Na pequena povoação de Campo Benfeito, da freguesia de Gosende, nos finais dos anos oitenta estabeleceu-se um grupo de jovens que acabou por ali formar uma companhia de teatro residente que hoje tem nome nacional e internacional fazendo espectáculos por todo o país e estrangeiro. A aldeia, de 67 habitantes, estava em pleno processo de desertificação de tal forma que a escola primária já havia fechado portas pois não havia qualquer criança que a frequentasse. $\mathrm{O}$ aparecimento desses jovens estrangeiros, um dos quais ali se estabeleceu e ali casou, fez com que outros ali ficassem também, resistindo aos apelos do exterior e ali constituindo famílias. Os homens formaram a companhia "Teatro Regional da Serra do Montemuro", enquanto as mulheres se juntavam numa cooperativa chamada "As Capuchinhas" que passou a dedicar-se à confecção de roupas. Do casamento dos elementos da companhia teatral com as mulheres das "Capuchinhas" nasceram seis crianças que vieram pôr fim 
ao processo de desertificação. Em 1998, os elementos do TRSM criaram um festival de teatro, o "Altitudes", que ultrapassou já o carácter regional e nacional com que começou e de nacional passou a internacional e no verão é ver os amantes do teatro deslocarem-se em direcção a Campo Benfeito onde vão encontrar espectáculos de grande nível e onde "Lavrador senta-se ao lado de juiz, operário ao lado de empresário, reformado ao lado de jovem desempregado", como se lê no sítio Internet da companhia.

A cooperativa das Capuchinhas apostou forte nos tecidos e métodos de fazer tradicionais, nomeadamente o burel e o linho. Os teares saíram dos seus esconderijos, o burel passou a ser decorado com muitos motivos, alguns deles bem tradicionais e retirados da decoração das capuchas, o linho passou a fazer parte integrante da moda que, com um moderno design, faz as delícias de portuguesas e estrangeiras e até uma família real de um país europeu já se apaixonou por aqueles tecidos e aquelas vestimentas. E onde se instalaram as Capuchinhas? Na antiga escola desactivada que assim continua a ter uma utilização ao serviço da comunidade.

Mas nem só as roupas seguem os moldes tradicionais, pois o teatro também tem vivido imenso dos temas regionais, inventando textos baseados em realidades locais que tanto pode ser a emigração como qualquer história ou lenda local construídas e encenadas pelos próprios elementos da companhia.

No caso de Campo Benfeito temos a mistura da cultura pura e dura, com o teatro e com os tecidos produzidos por uma forma de saber fazer ancestral aprendido com as mulheres mais velhas da povoação.

Dissemos atrás que um processo de desenvolvimento tem que ser integral e total. Também a este nível o que se passa em Campo Benfeito é significativo, pois é contagiante e emocionante assistir à discussão entre os elementos da companhia e os habitantes da aldeia que assim sentem o teatro como seu. Este caso é bem a mostra de um processo integral e de envolvimento da população que colabora fortemente com os actores do Teatro Regional da Serra do Montemuro e as costureiras das Capuchinhas.

Outros exemplos se poderiam apontar como o caso de El Ciego, a pequena localidade espanhola de La Rioja que saltou para as páginas dos jornais e se tornou num dos grandes destinos turísticos de Espanha quando as caves do Marquês de Riscal encomendaram um hotel e umas novas caves a Frank Gehry. E é de salientar que, no caso de Bilbao e de El Ciego, estamos a falar de edifícios recentemente construídos e não de edifícios antigos considerados como património edificado antigo. A este nível que dizer de Roma ou de Barcelona, por exemplo, uma mais antiga, com edifícios romanos com dois mil anos e outra mais recente e com os 
edifícios principais a terem pouco mais de um século? Os milhões de turistas que entram nestas cidades devido ao património arquitectónico trazem à economia da cidade proventos enormes e fazem movimentar milhões e milhões de euros e manter e criar milhares de postos de trabalho.

Este aspecto da ligação da cultura e do Património ao turismo é uma questão essencial sempre que se fala do Património e do desenvolvimento. O património tangível ou intangível é constituído por um conjunto de objectos, materiais ou imateriais que são o resultado da selecção que as gerações vão fazendo ao longo dos séculos e são uma forma consciente de o homem, no seu subconsciente, tentar atingir a imortalidade, ideia consciente que o homem desde sempre perseguiu. Ora, as tradições que temos e que transmitimos, os edifícios que herdámos e vamos conservar, os edifícios que deixamos degradar e abandonamos, tudo isso serve para recordar, para tentar esquecer, mas são sempre a herança e a recordação e, ao mesmo tempo, a forma de o homem imortalizar a sua memória. É este património, mesmo inatingível porque imaterial, que deve ser tido em conta na construção de qualquer projecto de desenvolvimento. Este património cultural mobiliza hoje milhões de pessoas que se deslocam de um lado para o outro para ver e ter sensações novas. Apontámos já Foz Côa e Campo Benfeito como bons exemplos portugueses de projectos para o futuro. Em termos de património construído e monumental muito mais se poderia e deveria fazer. O Douro, por exemplo, de que estamos aqui próximos e que foi classificado como Paisagem da Humanidade encerra uma riqueza extraordinária de património construído de todas as épocas e recebe hoje cerca de 300.000 pessoas por ano. Ora, quantas destas pessoas se demoram no Douro a ver o seu património? O que sucede é que as pessoas são metidas num barco no Porto, almoçam no barco ou saem para almoçar em Alpendorada ou qualquer outro sítio previamente marcado, prosseguem viagem até à Régua onde podem sair ou não, visitam, por vezes, Lamego e S. João de Tarouca, vão ao Pinhão onde fazem uma prova de vinho do Porto e prosseguem até Barca d'Alva ou regressam ao ponto de partida.

Ao longo deste percurso há um património enorme, sobretudo medieval e moderno, que não é visitado porque é desconhecido e, consequentemente não valorizado. Por si só os monumentos românicos e medievais mereciam ser valorizados para serem visitados. Vejamos um exemplo concreto. O concelho de Tarouca tem a igreja de S. Pedro de Tarouca, os mosteiros de S. João de Tarouca e Santa Maria de Salzedas e a ponte da Ucanha. Ora, estes monumentos estão fechados ou estão abertos graças à boa vontade de alguém que guarda a chave ou porque a 
Câmara Municipal e a paróquia estabeleceram um protocolo que mantém a porta aberta.

Os números não oficiais, porque os oficiais não existem, dizem que no mosteiro de S. João de Tarouca entram 70.000 visitantes por ano. Ora, se pensarmos que estas pessoas poderiam pagar só que fosse 1 euro por entrada isso representava 70.000 euros por ano. Mas imaginemos que estas mesmas pessoas eram encaminhadas para Salzedas e a ponte medieval da Ucanha e então o bilhete comum custava 5 euros. Isto representaria 350.000 euros por ano. Digam-me se este dinheiro não dava para suportar uma administração comum a estes três monumentos com um quadro constituído por meia dúzia de técnicos que ainda poderiam fazer restauros e outras coisas do género na região. Pense-se ainda que esta mesma administração era comum aos monumentos mais próximos de Ferreirim e Lamego ou mesmo Armamar e Tabuaço. Em vez de 350.000 euros/ano poderia haver uma entrada de dinheiro de meio milhão de euros e em vez de meia dúzia de postos de trabalho poderia haver uma dúzia. $\mathrm{E}$ os benefícios indirectos que esta situação traria são incomensuráveis: unidades hoteleiras, restauração, produção de produtos endógenos (agrícolas e artesanais), casas de turismo... O futuro da gestão patrimonial passa forçosamente pela criação de áreas culturais que englobem vários monumentos geridos em conjunto e estejam sujeitas às mesmas regras, com uma descentralização muito grande e em que os fundos gerados sejam em grande parte mantidos e investidos no local, independentemente da solidariedade nacional que deve existir.

$\mathrm{O}$ interior e o seu desenvolvimento têm que ser equacionados em função da realidade existente e não em função das ideologias ou das utopias que cada um possa construir e a realidade é que o turismo com base na cultura e no património, a que se deverá juntar o ambiente, são as peças essenciais para salvar o interior da desertificação pelos postos de trabalho que podem criar, pelo relançamento de actividades tradicionais que podem proporcionar, pelo dinheiro que podem injectar nas economias deprimidas.

No Alentejo, a Câmara Municipal de Mora abriu em Março de 2007 um Fluviário, única estrutura do género existente em Portugal. Visitaram até agora o Fluviário, ao fim de um ano e meio, mais de 300.000 pessoas que fizeram entrar nos cofres da autarquia mais de dois milhões de euros. O êxito é tal que já estão a ser feitas obras de ampliação com parte do dinheiro gerado e estão a ser apoiadas instituições da vila com esses mesmos fundos. Não há números para as alterações que se processaram na vila de Mora, mas posso relatar, por conversas pessoais em cafés e numa fábrica de pastelaria existente na vila, que o movimento aumentou extraordinariamente, as vendas nos cafés igualmente e até a aldeia de Pavia, próxima de Mora, viu os visitantes da anta/capela local e do museu 
local aumentarem muito, segundo o relato dos próprios habitantes. São os efeitos co-laterais benéficos da estrutura ali construída.

A autarquia local não esperou que o Estado central viesse resolver o problema, mas procurou a sua própria solução e encontrou efectivamente no nicho ambiental a solução para alguns dos seus problemas. Apontamos este exemplo que é bem demonstrativo da mentalidade que deveria existir mas tarda a aparecer em muitos outros lugares que é o da iniciativa local para resolver os problemas.

Semear para colher terá que ser o objectivo de um projecto de desenvolvimento. Ora, na cultura parece que muitas vezes pretende-se colher sem semear e todos os cêntimos atribuídos à cultura são considerados como um desperdício. É esta ideia generalizada que tem que mudar, se o país quiser alterar o estado das coisas neste momento, pondo as regiões interiores a produzir e exportar cultura e pondo o património a render dinheiro porque, como fica demonstrado, é possível. Investir na Cultura e no Património no interior é promover o desenvolvimento e salvar o futuro desse mesmo interior. 